\title{
Las voces de la música. Una reflexión previa ${ }^{1}$
}

\section{Entries on Music. Preliminary Thoughts}

Este trabajo supone una primera aproximación a algunos de los aspectos que definen la estrecha relación de la música con su léxico. Reivindicamos que la palabra, como reverso de la realidad, es una fuente igualmente válida para proponer nuevos acercamientos a la historia de la música, cuyo estudio, por otra parte, reclama un espacio propio y autónomo. Desde este punto de vista trataremos aspectos como la naturaleza diferenciada de los lenguajes de especialidad respecto a la lengua común, los contactos de las unidades léxicas de la música con la lengua general así como las múltiples aplicaciones historiográficas que un estudio científico de las voces de la música puede ofrecer a la narrativa musicológica. Por último, expondremos algunos presupuestos metodológicos inspirados en la lingüística de corpus adecuados para iniciar una investigación sobre el léxico de la música.

Palabras clave: unidades léxicas de la música, léxico de la música, lexicografía, lexicología, historia de la lengua, historiografía, diccionarios de música.

This article is a first attempt at examining some of the aspects that define the close relationship between music and its lexicon. It asserts that words, as the underside of reality, are an equally valid source for proposing new approaches to music history, whose study, on the other hand, requires a space of its own. This viewpoint forms the basis of the study of issues including the differing nature of specialised languages in relation to a common language, the connections between the lexical units of music and general language, as well as the many historiographical applications that an academic study of the entries on music can offer the musicological narrative. Finally, the article will outline some methodological premises inspired by corpus linguistics suitable for beginning research into the lexicon of music.

Keywords: lexical units of music, lexicon of music, lexicography, lexicology, history of language, historiography, music dictionaries.

Hace mucho que la musicología ha asumido que la práctica historiográfica no es solo un intento de ordenación de una suma de secuencias que empiezan y acaban en el acto sonoro. La música es mucho más que "un juego sin objeto con los sonidos"2. Como realidad extralingüística está, sin embargo, mediada por el lenguaje. Por ello, la historia de la música es necesariamente discurso y, por tanto, también palabra. Como señala Henry Raynor, "cuando seguimos el camino por el que se han desarrollado el

${ }^{1}$ Este artículo se enmarca dentro de las actividades del Proyecto I+D "MadMusic. Espacios, géneros y públicos de la música en Madrid, ss. XVII-XX". Comunidad de Madrid, Ref. S2015/HUM-3483 (2016-2018).

${ }^{2}$ Henry Raynor: Una historia social de la música. Desde la Edad Media hasta Beethoven, Madrid, Siglo XXI de España, 1986, p. 7. 
vocabulario, la gramática y la sintaxis de la música, revelamos con mayor claridad una variedad de problemas que la historia estilística no está capacitada para contestar"'. Así, la palabra, como reverso de la realidad y como vía de acceso igualmente válida al hecho musical, es una fuente para descubrir sutilezas, captar matices y descifrar secretos que muchas veces han escapado al relato historiográfico.

Desde este punto de vista, y partiendo de los problemas que surgen en el estudio de las unidades léxicas de la música ${ }^{4}$, se presentan a continuación una serie de reflexiones de índole lingüística con la intención de abrir el debate e invitar a la reflexión a toda la comunidad musicológica. En concreto, se tratarán los siguientes puntos: 1) las múltiples posibilidades que una investigación de corte lexicológico y lexicográfico ofrece a la narrativa musicológica; 2) la naturaleza de las unidades léxicas de la música, sus contactos con la lengua general y las conclusiones que la musicología puede obtener a partir de esta realidad; y 3) los presupuestos metodológicos más adecuados para iniciar un acercamiento lexicográfico a un ámbito de especialidad como la música de cualquier naturaleza (onomasiológica o semasiológica), alcance (sincrónico o diacrónico, por ámbitos temáticos o general) y magnitud (en forma de repertorio lexicográfico o como aproximaciones particulares en torno a voces o conceptos concretos). En definitiva, lo que defendemos desde estas páginas es que tanto la esencia de la música como su representación nominal funcionan como dos caras de una misma moneda.

\section{Un ejercicio de musicología aplicada. Las múltiples proyecciones de una investigación lingüística de las voces de la música}

Como punto de partida, hay que asumir una premisa fundamental: las unidades léxicas de la música no solo identifican conceptos estáticos, monolíticos, uniformes y cerrados que pertenecen a un campo concreto del conocimiento humano cuyo funcionamiento podría reducirse, en última instancia, a su papel como sustitutas de realidades de la disciplina a la que pertenecen. Muy al contrario, estas unidades poseen una trayectoria propia e integran al mismo tiempo aspectos discursivos, cognitivos y sociales de gran complejidad. Su documentación y estudio puede enriquecer de manera significativa el relato historiográfico de la música. Por estas razones,

\footnotetext{
${ }^{3}$ Ibid., p. 7.

${ }^{4}$ Empleamos una formulación así de general (unidades léxicas de la música) con la intención de abarcar en toda su totalidad y complejidad un espacio, el del lenguaje de un ámbito como la música, donde conviven piezas léxicas de muy diversa naturaleza. Seguimos, en este sentido, a María Teresa Cabré: La terminología. Representación y comunicación, Barcelona, Institut Universitari de Lingüística Aplicada, Universitat Pompeu Fabra, 2005.
} 
se ha venido reivindicando desde mediados del siglo XX, sobre todo en el ámbito internacional ${ }^{5}$, la necesidad de constituirlas en objeto de estudio desde planteamientos metodológicos propios.

Conviene tener en cuenta este fenómeno a la hora de hacer una lectura crítica de las numerosas tentativas pretendidamente lexicográficas con las que contamos en la bibliografia en español. Encontramos desde fechas tempranas del siglo $\mathrm{XIX}^{6}$ una gran cantidad de obras denominadas diccionarios de música que, inspiradas por un admirable afán de recoger unidireccionalmente la nomenclatura de un vastísimo y diverso ámbito del conocimiento humano resultan, sin embargo, parciales. En parte porque se da una confusión en su planteamiento original ${ }^{7}$. De hecho, la extensa

\footnotetext{
${ }^{5}$ En Alemania destacan los trabajos de Hans Heinrich Eggebrecht: "Terminus Ricercare", Archiv für Musikwissenschaft, 9, 1952, pp. 137-147; id.: "Ein Musik-Lexikon von Christoph Demantius", Die Musikforschumg, 10, 1957, pp. 48-49; id.: "Aus der Werkstatt des terminologischen Handwörterbuchs", Kongressbericht der Int. Ges. F. Musikwissenschaft, 5th congress, 1952 [1953], pp. 155-165; id.: Musikalisches Denken. Aufsätze zur Theorie und Ästhetik der Musik, Wilhelmshaven, Heinrichshofen, 1977, pp. 113-129; id.: Handwörterbuch der musikalischen Terminologie, Wiesbaden, F. Steiner, 1972-; id.: Studien zur musikalischen Terminologie, Maguncia, Wiesbaden Akademie-Steiner, 1968 (Akademir der Wissenschaften und der Literatur). También en el ámbito alemán encontramos más recientemente estudios como los de Markus Bandur: "Die Fachlexikographie der Musikwissenschaft", Fachsprachen. Languages for Special Purposes, L. Hoffmann, H. Kalverkämper, H. E. Wigland (eds.), Berlín-Nueva York, Walter de Gruyter, 1999, vol. 2, pp. 2005-2013. Por su parte, en el contexto italiano se han impulsado de unos años a esta parte proyectos como Lesmu, Léxico musical italiano (dirigido por Franco Cesati) o aquellos que Gianmario Borio repasa en monografías como Gianmario Borio: "Parola-musica-contesto: l'evoluzione storica dei concetti musicali", Storia dei concetti musicale: Melodia, stile, suono, Gianmario Borio (ed.), Roma, Carocci Editore, 2009, pp. 13-23. En el caso del español podemos destacar sobre todos el trabajo pionero de Louis Jambou y su proyecto Léxico Musical del Renacimiento iniciado en 1997 y que ahora dirige Cristina Diego Pacheco. Y en lo particular, se puede observar cómo la reflexión lingüística va ocupando cada vez más un mayor espacio en monografías o tesis doctorales. De igual manera, últimamente están apareciendo más investigaciones que desde la musicología se centran en el apartado lingüístico. Destacan Cristina Diego Pacheco: "El léxico musical del renacimiento: premisas para un estudio", Francisco de Salinas. Música, teoría y matemática en el Renacimiento, Amaya García Pérez y Paloma Otaola González (eds.), Salamanca, Ediciones Universidad de Salamanca, 2014 https://gredos.usal.es/ jspui/bitstream/10366/131598/1/978-84-9012-406-2-0189-0203.pdf (consulta 3-7-2017); Juan José Carreras: "Música nacional, historia de un concepto", El pentagrama político. Ensayos sobre música y nacionalismo, E. Ucelay-Da Cal, A. Colorado y M. Lloret (eds.), Grupo de Investigación en Estados, Naciones y Soberanías, Universidad Pompeu Fabra-Ministerio de Educación de España, 2016, pp. 20-36, http://grens.weebly.com/publicacions.html (consulta 3-7-2017); Juan José Carreras: "Nación, música nacional, nacionalismo", La música en España en el siglo XIX. Historia de la Música en España e Hispanoamérica, vol. 5, Juan José Carreras (ed.), Madrid-México D. F., Fondo de Cultura Económica, en prensa; Álvaro Torrente: "Cuando un 'estribillo' no es un estribillo: sobre la forma del villancico en el siglo XVII", El villancico en la encrucijada. Nuevas perspectivas en torno a un género literario-musical (ss. XV-XIX), Esther Borrego y Javier Marín (eds.), Kassel, Reichenberger (en prensa).

${ }^{6}$ Para un repaso a esta nómina de tentativas lexicográficas aplicadas al ámbito de la música puede consultarse la entrada correspondiente a "diccionarios" en Diccionario de la música española e hispanoamericana, Emilio Casares Rodicio (dir.), Madrid, SGAE, 1999-2002, vol. IV, pp. 498-505.

${ }^{7}$ La confusión o, más bien, la libertad con que se ha empleado el término enciclopedia o diccionario indistintamente para identificar cualquier ordenamiento sistemático del conocimiento siguiendo un orden alfabético olvida un aspecto crucial: el de la propia naturaleza de dos géneros y dos metodologías cuyos objetivos distan bastante entre sí. Para más información, véase José-Álvaro Porto Dapena: Manual de técnica lexicográfica, Madrid, Arco / Libros, 2002.
} 
nómina de diccionarios publicados en español comparte más rasgos con el género de la enciclopedia que con el del diccionario, tanto en el fondo como en la forma. Principalmente por las siguientes razones: 1) las entradas biográficas y los antropónimos conforman el grueso de la nomenclatura; 2) sus páginas se dedican primordialmente a la reflexión científica e historiográfica a través de artículos extensos; 3) no pretenden establecer un método lexicográfico sistematizado para presentar su información; y 4) su atención se centra en lo referido, en lo designado, eclipsando casi por completo a la información lingüística en su más amplio sentido.

La consecuencia es que la abierta inclinación enciclopédica que ha caracterizado a los diccionarios de música que ha producido la musicografia en español ha minimizado el potencial que encierra el signo, su carácter dinámico y discursivo, sus posibles ambigüedades derivadas de fenómenos históricos o socioculturales con los que, sin embargo, la musicología se encuentra continuamente. Por ello, sería deseable una investigación concentrada en las unidades léxicas de la música que indague en las huellas sonoras que, como veremos, también pueden rastrearse en las palabras con objeto de enriquecer el relato de las secuencias que componen la historia de la música ${ }^{8}$.

Desde este punto de vista integrador, el planteamiento de un estudio científico de las voces de la música proyecta sus avances al menos en tres direcciones. En primer lugar, se inscribe dentro de una corriente de la lingüística que en los últimos años ha comenzado a tener en cuenta los lenguajes de especialidad así como las dificultades que su tratamiento comprende para la lexicología y la práctica lexicográfica. En este sentido, un acercamiento a las unidades léxicas de la música de cierta magnitud constituiría una verdadera herramienta para los historiadores de la lengua. En segundo lugar, habría que destacar la enorme proyección musicológica de una investigación que, recordemos, se formula desde una publicación especializada en música. ¿No resulta evidente que la búsqueda de etimologías, pero también de información pertinente acerca de la lengua de procedencia de cada vocablo, de su cronología de incorporación, sus vías de penetración o usos históricos son de enorme utilidad para la musicología? En su intento de ubicar y periodizar los momentos en los que el español recibió según qué léxico y, por tanto, según qué realidades musicales, la musicología necesariamente tiene que acudir a la investigación lingüística. Y este es solo un ejemplo. Por último, un acercamiento científico a las palabras de la música de esta índole contribuiría a un manejo más preciso de la terminología de un dominio especializado. Debe tenerse en cuenta

\footnotetext{
${ }^{8}$ Como evidencia el hecho de que cada vez ocupan más espacio en la literatura musicológica las reflexiones centradas en los significantes de la música.
} 
que, además, este sigue incorporando de manera continua nueva nomenclatura con neologías asociadas a prácticas musicales del ámbito de la música popular y de vanguardia o a nuevas técnicas analíticas, compositivas e interpretativas. En este sentido, una ideal repertorización del léxico de la música en forma de diccionario que atienda a las perspectivas que aquí se presentan sería de gran utilidad a multitud de usuarios con intereses diversos. Más allá de la especialización musicológica, los profesionales o aficionados e incluso el público general podrían reforzar el conocimiento de una disciplina como la música. Sus resultados incluso ayudarían a revitalizar la imagen pública de esta dando un paso más en su inserción en el contexto sociocultural de la comunidad hispanohablante. Como recuerda María Teresa Cabré:

Más allá del interés profesional, también los individuos de a pie, habitantes del mundo que se caracteriza por la difusión de la información, la extensión del conocimiento y la vulgarización del saber especializado, necesitan imperiosamente la terminología para moverse en sociedad, para participar del proceso de progreso y, en suma, para sentirse habitantes del mundo avanzado?.

\section{Las unidades léxicas de la música, la lengua general y la musicografia}

Como se ha señalado, el análisis de las unidades léxicas de la música, en cuanto lenguaje especializado y como terminología (si entendemos terminología como el conjunto de términos o vocablos propios de determinada profesión, ciencia o materia ${ }^{10}$ ), plantea a la lexicología y a la lexicografía una serie de problemas derivados de su naturaleza diferenciada respecto a la lengua general. Su tratamiento y alcance ha constituido y constituye, de hecho, una de las dificultades históricas a las que se alude desde los inicios de la lexicografía moderna. De aquí se deriva, por ejemplo, la confusa relación de los lenguajes especializados, temáticos, marcados diatécnicamente y por tanto apartados de la lengua común no marcada, con los diccionarios generales ${ }^{11}$. En este sentido, el estudio lingüístico de las unidades léxicas de la música presentará diferencias con el de las unidades de la lengua general

\footnotetext{
${ }^{9}$ María Teresa Cabré: La terminología..., p. 34.

${ }^{10}$ Real Academia Española: Diccionario de la lengua española, 2014, 23. ${ }^{a}$ ed., http://dle.rae.es/ ?id=DgIqVCc (consulta 3-7-2017).

${ }^{11}$ Julio Fernández Sevilla, como otros tantos autores, ha subrayado lo complejo que resulta discernir las fronteras entre el vocabulario corriente (el apto para ser contenido en un repertorio de lengua general) y el vocabulario técnico (objeto de otro tipo de repertorios especializados) dado que existen trasvases continuos entre ambos niveles. Julio Fernández Sevilla: Problemas de lexicografía actual, Bogotá, Publicaciones del Instituto Caro y Cuervo,, 1974, p. 123. Este fenómeno, trasladado al caso del español, ha provocado, junto a otros factores, el precario estado actual del vocabulario de la música en el repertorio académico.
} 
ya que de partida el vocabulario técnico, científico o de las artes presenta mayor restricción en sus usos y significados que las unidades de la lengua común. Sin embargo, reconocer que como terminología el lenguaje de la música obedece a conceptos de univocidad, monosemia e incluso universalidad, como la teoría clásica de la terminología de Eugen Wüster postuló en su momento ${ }^{12}$, resulta insuficiente. La concepción ortodoxa del austríaco presenta, según María Teresa Cabré, "los términos como unidades específicas de un ámbito de especialidad; considera que su valor se define solo por su inserción en este ámbito, y caracteriza el término como una unidad de carácter plano en su contenido, en sus funciones y en su uso" ${ }^{13}$. Sin embargo, como muchos autores han señalado posteriormente, entre el vocabulario corriente, subjetivo y propiamente lingüístico y el vocabulario objetivo, en referencia a las terminologías, se da una relación simbiótica ${ }^{14}$.

Profundizar en un acercamiento a las palabras de la música desde la perspectiva ortodoxa de Eugen Wüster implicaría, en definitiva, negar la capacidad de variación formal y conceptual de las unidades léxicas de la música al considerarlas elementos ajenos al contexto, al lenguaje y a la comunicación. No atender a los posibles fenómenos de tipo sintáctico, discursivo o contextual que comportan implicaciones cruciales para la investigación musicológica y la historia de la lengua podría conducir a una visión problemática de la historia de la música. Porque evillancico, estribillo, zarzuela, ópera o tono, significantes constantes, han denominado siempre a una realidad musical estable y unívoca independientemente de la época o el contexto discursivo en que se han empleado? No lo parece, como recientes trabajos $^{15}$ han demostrado al intentar discernir las complejas relaciones derivadas del encaje entre el concepto y el significante, entre lo referido y su forma léxica, entre el contenido y la forma de determinadas voces de la música y las consiguientes confusiones derivadas.

En este sentido, incluso en muchas ocasiones no resulta sencillo identificar unidades con valor puramente designativo que se refieran a conceptos cerrados del arte musical, es decir, con una relación entre significante y significado unívoca y monosémica. A primera vista podríamos ubicar en este apartado las unidades léxicas relativas a la teoría y técnica musicales como tónica, subtónica, mediante... (los grados de la escala) o do, re, mi, fa... (los nombres de las notas). No obstante, en ambos casos habría que matizar que solo sincrónicamente y en un contexto tonal las unidades léxicas

\footnotetext{
12 Véase Eugen Wüster: Introducción a la teoría general de la terminología y a la lexicografía terminológica, Barcelona, Institut Universitari de Lingüística Aplicada, Universitat Pompeu Fabra, 1998.

${ }^{13}$ M. ${ }^{a}$ T. Cabré: La terminología. Representación..., p. 115.

${ }^{14}$ J.-Á. Porto Dapena: Manual de técnica lexicográfica..., p. 49.

15 Véase J. J. Carreras: "Música nacional, historia de un concepto"..., J. J. Carreras: "Nación, música nacional, nacionalismo" y A. Torrente: "Cuando un 'estribillo' no es un estribillo...".
} 
referidas a los grados de la escala y los nombres de las notas se comportan unívocamente. A este respecto conviene no perder de vista que en la teoría hexacordal, con vigencia entre los siglos XI y XVI, cada nota de la escala podía ser representada por más de una sílaba dependiendo de su posición en el hexacordo, lejos, efectivamente, de establecerse una relación cerrada y unívoca. Es una realidad, por tanto, que los términos de la música no son una unidad meramente con función denominativa. Al contrario, dentro de las unidades léxicas de la música se identifican piezas altamente polisémicas y equívocas cuyo significado varía en función de numerosas variables tanto de su historia como del ámbito comunicativo ${ }^{16}$.

También pueden albergar interés para la musicología otro tipo de fenómenos como el contacto del léxico de la música con la lengua general y la consiguiente imitación de muchos de sus comportamientos. En cuanto a lo estrictamente gramatical, sobre los términos de la música actúan sin excepción las propiedades morfológicas y de formación del español (así desde jazz pueden formarse jazzista, jazzero, jazzístico, jazzísticamente y jazzear). Este aspecto, el de la derivación, debería resultar ineludible a la hora de introducir y poner en circulación voces neológicas de acuerdo con las reglas del propio sistema lingüístico. Igualmente, en las unidades léxicas de la música se encuentran relaciones paradigmáticas (como do, re, mi, fa, etc. y nota, hipónimos e hiperónimo respectivamente) y sintagmáticas: todas aquellas que tienen que ver con el seguimiento de una combinatoria léxica regulada por las restricciones y los requerimientos argumentales de las piezas predicativas (alguien acompaña A alguien A instrumento musical -con art. definido-, Iuan acompañó A Miguel A la guitarra). También como parte del componente sintagmático que define a las unidades léxicas de la música se puede explicar el hecho de que, en ocasiones, expresiones a primera vista análogas son resultado de distintos contextos semántico-sintácticos (cantar el contrapunto y echar el contrapunto funcionan con distintos matices).

Por otro lado, los vocablos que pertenecen al dominio de la música están sujetos a dinámicas internas al presentar en muchas ocasiones fenómenos como el polimorfismo (semicopado>sincopado, minué/minueto, ritornelo/retornelo, cantata/cantada, castrato/castrado, trítono/tritono, tímpani/timbal). Mientras unas formas se han afianzado, otras han retrocedido e incluso desaparecido.

${ }^{16}$ A este respecto, María Teresa Cabré considera que "ciertamente, una terminología especializada destinada a representar el conocimiento in vitro no requiere las mismas condiciones que una terminología que tiene que circular in vivo. [...] La terminología fundamentalmente representacional puede ser perfectamente artificial y arbitraria, y puede controlar al máximo la variación, preservando, pues, el principio de univocidad y monosemia de la teoría clásica. La terminología básicamente comunicacional natural, en cambio, debe ser necesariamente real, en el sentido que tiene que ser efectivamente, directamente y fundamentalmente utilizada, y, si es real, presenta variación”. M. T. Cabré: Terminología. Representación..., p. 79 y ss. 
Discernir si las causas obedecen a cuestiones puramente lingüísticas o, por el contrario, están motivadas por aspectos sociales, historiográficos o de cualquier índole es una investigación útil para la musicología que atañe igualmente a la lingüística.

Además, el lenguaje de la música también es prolijo a la hora de crear modismos, locuciones, patrones morfo-sintácticos, organizaciones textuales fijas, fraseológicas e incluso paremiológicas. Es el caso de música ratonera, echar el contrapunto/cantar el contrapunto, hacer hablar (A un instrumento), herir la cuerda, a bombo y platillo, echar las campanas al vuelo, oír campanas y no saber dónde, juntarse a campana tañida; campana cascada nunca sana; a la moza mala, la campana la llama; gente ruin, campana de palo, etc.

Abundando en la vitalidad del lenguaje de la música respecto a la lengua general se observa asimismo cómo según qué fenómenos se muestran pertinentes para la historiografia de la música. Es el caso, en primer lugar, de la cantidad de voces terminológicas que han pasado a la lengua usual como contrapunto; ritornelo; acompasar (>compás); melodrama; homofonía; melodía; prima donna; entonar (desentonar); polifonía/polifónico; leitmotiv; monocorde... En este sentido, la plasmación definitiva del grado de circulación de numerosas unidades léxicas de la música en la lengua general puede advertirse en la capacidad de metaforización que determinadas voces han tenido para el caso del español. Esto es: la capacidad de ciertas palabras para adquirir significados figurados como en los casos de melodrama, bemoles, charanga, mitote ${ }^{17}$, milonga o tonada. En relación con los aspectos de uso que también afectan a las palabras de la música (rectos o figurados), el comportamiento de muchas de estas también está sometido a acepciones de variedad, registro e incluso nivel de habla (porque ¿se emplean indistintamente charanga y banda aunque supuestamente aludan a una misma realidad?). Este tipo de unidades han llegado a funcionar como unidades del lenguaje ordinario, se han generalizado y han comenzado a compartir de pleno las características de la lengua general.Y de igual manera podemos identificar el fenómeno contrario: existen multitud de voces de uso común, palabras del léxico ordinario, que han pasado a utilizarse como tecnicismos o voces terminológicas en un proceso de especialización. Es el caso de voces como tónica, dominante, diferencia, afinar, frase, semifrase... Además, de forma paralela a los procesos de generalización y especialización, en muchas ocasiones encontramos ejemplos donde una misma unidad tiene vitalidad tanto en el ámbito

${ }^{17}$ El DLE registra hasta cuatro acepciones en la entrada mitote, voz originaria del náhuatl (mitoti, 'bailarín'): 1) Cierta danza indígena, en la que sus integrantes, asidos de las manos, formaban un gran corro, en medio del cual ponían una bandera, y junto a ella una vasija con bebida, de la que, mientras hacían sus mudanzas al son de un tamboril, bebían hasta que se embriagaban; 2) Guat. y Méx.: Melindre, aspaviento;3). Méx.: Fiesta casera; y 4) Méx.: Bulla, pendencia, alboroto. Véase Real Academia Española: Diccionario de la lengua española, 23. ${ }^{a}$ ed., 2014, http://dle.rae.es/?id=PQhHbPL, (consulta 3-7-2017). 
especializado como en la lengua común. Es el caso de milonga, mitote o melodrama. Este solapamiento de usos parece que es la evidencia de cómo una unidad conceptual o cognitiva, en este caso de la música, se presenta en diferentes versiones debido a que ciertos rasgos se diversifican o complementan según actúan en la lengua general o dentro de un ámbito especializado. Tener en cuenta este tipo de informaciones en repertorios especializados o trabajos musicológicos aporta sugerentes matices, nuevas variantes o, simplemente, información contextual a la historia factual.

Los que hemos tratado son algunos de los aspectos de interés para el estudio del lenguaje de la música.Y como vemos, corroboran que sus unidades léxicas no solo actúan como vehículo del conocimiento de un dominio de especialidad. De hecho, las estrechas relaciones que establecen estas con la lengua general demuestran la existencia de dinámicas que también se antojan pertinentes a la hora de elaborar el discurso de la musicología. La música participa, por ejemplo, de articulaciones sociales que estudiadas en detalle permiten sacar numerosas conclusiones incluso de índole cultural. ¿No parece que de fenómenos como la doble vitalidad de voces como milonga, mitote o melodrama o de la capacidad del sustantivo campana para crear modismos pueden extraerse conclusiones acerca del grado de transferencia de distintas realidades del hecho musical al contexto del pensamiento general?

\section{El rastro de las voces de la música. El trabajo de corpus}

Parece que la música deja rastro en sus palabras (y viceversa). Por tanto, una investigación científica de las unidades léxicas de la música de cualquier alcance y magnitud se debería enmarcar en una serie de criterios metodológicos validados por disciplinas como la lexicografia ${ }^{18}$. En este sentido, Juan José Carreras apunta una de las ideas fundamentales para llevar a cabo un estudio de corte lingüístico aplicado a la musicología al aludir a la necesidad de "recabar un amplio espectro de fuentes que, sin excluir las grandes referencias, incluyan textos como memorias de viaje, diccionarios, anuncios y polémicas de prensa, que permitan una reconstrucción histórica significativa de los distintos usos del concepto" ${ }^{19}$. De esta manera Carreras identifica dentro de las dinámicas discursivas en que se envuelve el léxico de la música, distintos ámbitos, niveles o espacios de uso del lenguaje de la música dado que esta no pertenece ni es exclusiva de sus profesionales. Por el contrario, las palabras de la música tienen rendimiento de igual manera en

\footnotetext{
${ }^{18}$ Huelga subrayar que la lexicografía es una disciplina científica cuya práctica no depende del buen criterio de un puñado de especialistas. Prima, por tanto, el rigor metodológico sin desdeñar que la intuición y el olfato son habilidades más que necesarias para el desempeño de una tarea lexicográfica.

19 J. J. Carreras: "Música nacional, historia de un concepto...", p. 3.
} 
círculos académicos y especializados, en ámbitos educativos que van desde la enseñanza primaria a la universitaria y en la lengua común. Entre medias, todavía hay espacio para la divulgación, la crítica o la literatura ${ }^{20}$. Como señala María Teresa Cabré, y como hemos visto también respecto a las unidades léxicas de la música, "la forma es constante, pero el contenido se singulariza en forma de selección de rasgos adecuados a cada tipo de situación y determinados por el ámbito, el tema, la perspectiva de abordaje del tema, el tipo de texto, el emisor, el destinatario y la situación" ${ }^{21}$. Este aspecto resulta crucial para un planteamiento de propósitos descriptivos y no normativos que pretenda indagar en las causas de las dinámicas que afectan a las unidades léxicas de la música y no a censurar sus usos. Es el ejemplo de género chico. Para un hablante medio del español, género chico remite, prácticamente como sinónimo, a zarzuela. No obstante, en el ámbito académico esta confusión de naturaleza metonímica es poco menos que un disparate. Legítimo o no, adecuado o no, este uso existe.Y más allá de reprobrarlo (si es que llegara a servir de algo), lo que resulta pertinente para la musicología es explicar su origen y extraer conclusiones.

Por tanto, dado que nuestro interés también se centra en lo discursivo, así como en el carácter poliédrico y en las dimensiones comunicativas, cognitivas y sociales a las que también obedecen las unidades léxicas de la música, parece evidente que la efectividad y la piedra de toque de un acercamiento científico a las palabras de un dominio especializado dependerá en buena parte del diseño de un corpus textual multidimensional. Este corpus, que de partida se plantearía en función de la orientación que se quisiera dar a la investigación, debería cumplir con los siguientes requisitos: 1) aglutinar un conjunto de testimonios amplio, diverso (en tipos y géneros de fuentes con distintas ópticas y motivaciones) y disperso (en ámbitos temáticos, procedencias geográficas y registros lingüísticos); y 2) incluir no única y exclusivamente documentos destacados por su valor enciclopédico o historiográfico sino, sobre todo, aquellos que revistan interés y rendimiento filológico; valorando, en definitiva, la calidad científica de los autores del canon pero sin dejar de ponderar la proyección y pertinencia de muchos otros tipos de textos que aglutinen todas las facetas de las palabras de la música. Esto supondría recopilar obras científicas, textos de revistas especializadas, enciclopedias, manuales de enseñanza secundaria y universitarios, pero también artículos de prensa, crítica, ensayística, textos literarios e incluso la transcripción de documentos sonoros procedentes de la televisión o la radio como representaciones de la lengua hablada.

${ }^{20}$ No hace falta recordar el evidente rendimiento y la vitalidad que las unidades léxicas de la música han ofrecido a lo largo de la historia para con los textos literarios.

${ }^{21}$ M. T. Cabré: La Terminología. Representación..., p. 123. 
Mediante este proceder inspirado en la lingüística de corpus podrían procesarse y posteriormente realizarse análisis de frecuencia y dispersión de las unidades léxicas para así poder ubicar cuándo determinadas palabras se afianzan, retroceden o desaparecen, determinar el índice de utilidad y empleabilidad de cada término (minué frente a minueto), restringir los diferentes usos y contextos en que aparecen según que unidades léxicas (charanga frente a banda), identificar colocaciones habituales (como cantar y echar el contrapunto), el grado de vitalidad que las unidades léxicas de la música poseen en la lengua común, etc. En definitiva, el trabajo de corpus permitiría comprender el dinamismo y la riqueza del léxico de la música y, lo que es más importante, inspirar nuevas conclusiones a la musicografia al arrojar luz sobre cuestiones que en muchas ocasiones han pasado o pueden pasar desapercibidas.

No obstante, la utilidad de esta metodología no acaba en este punto. A partir de las múltiples conclusiones que se extraen del trabajo de corpus podría incluso consensuarse, ya basados en testimonios documentales y de forma científica, las características de un hipotético proyecto lexicográfico en forma de diccionario. Así resultaría más sencillo decidir: 1) su macroestructura, es decir, todo aquello que tiene que ver con la selección de la nomenclatura y la forma más adecuada de presentar el material y ordenar las entradas, lemas, sublemas, acepciones, subacepciones, variantes contextuales si las hubiese, etc., para poner en orden las múltiples cosas y acepciones de cada unidad léxica y desentrañar sus relaciones de sentido ${ }^{22} ; y, 2$ ) su microestructura, esto es, la información interna de los respectivos artículos lexicográficos, lo que incluye una de las tareas más delicadas y sensibles de todo repertorio lexicográfico: la redacción de las definiciones o explicaciones de cada vocablo seleccionado ${ }^{23}$.

\footnotetext{
${ }^{22}$ Como en los casos de tono, villancico, cadencia, etc. No obstante, a este respecto conviene recordar que el registro de todos y cada uno de los usos particulares de las unidades de una determinada nomenclatura propuesta no es una práctica viable. Recoger todos y cada uno de los usos, por autores, por ejemplo, sería una tarea imposible y supondría algo así como plantear un impracticable diccionario del habla registrando todos y cada uno de los usos que a lo largo de la historia han adquirido determinados vocablos relacionados con la música. Si bien la lexicografía ha de captar las sutilezas que encierra el lenguaje, no debe olvidar que su tarea también consiste en buscar generalizaciones.

${ }^{23}$ Cada unidad léxica puede ser definida desde diversas perspectivas: "por su significado, por su significante o por su funcionamiento sintáctico o pragmático; pero, a su vez, por ser precisamente un signo, representa una realidad en sí misma, la cual puede ser asimismo objeto de definición”. J.-Á. Porto Dapena: Manual de técnica lexicográfica..., p. 277. Las unidades léxicas de la música, por tanto, pueden describirse como un conjunto de rasgos o características. Y por ello el análisis sémico (rasgos sémicos constitutivos, los diferenciales y opositivos, etc.) resulta imprescindible a la hora de elaborar una definición. No obstante, intentar abarcar todo el potencial semántico de una unidad léxica es un proceso complejísimo y que depende en gran medida de la naturaleza de cada unidad léxica. Además, ¿por qué rasgos distintivos nos inclinaríamos para elaborar nuestras definiciones?, porque itodos los hablantes consideran lingüísticamente pertinentes los mismos? La respuesta a ambos interrogantes no parece sencilla.
} 


\section{Recapitulación}

El contenido de la presente reflexión parte de un propósito concreto: reivindicar la trascendencia de una nueva mirada al hecho musical desde el estudio riguroso de su léxico. Como se ha argumentado, la música y sus palabras funcionan como dos caras de una misma moneda cuya relación en sí misma ofrece una gran cantidad de información pertinente. En este sentido, aquí solo se ha planteado un esbozo de una serie de aspectos y dinámicas que afectan a las unidades léxicas de la música con el ánimo de abrir el debate, servir de inspiración y apuntar algunas calas en su estudio.

Asimismo, desde estás páginas hemos aludido a las múltiples aplicaciones y utilidades historiográficas que puede llegar a poseer un acercamiento a las palabras de la música a la hora de calibrar aspectos como su imagen pública. Al igual que la campana, que ha trascendido su naturaleza sonora para convertirse en un elemento urbano y cotidiano cuya plena integración social se evidencia en la capacidad que como sustantivo ha tenido a lo largo de la historia para crear modismos, otras muchas realidades musicales han logrado una importante recepción en el mundo conceptual de los hablantes de una sociedad dada en un momento determinado. Profundizar en estos fenómenos abre un campo de estudio cuanto menos sugerente.

Por otra parte, si bien es cierto que un lenguaje de especialidad como el de la música presenta mayor restricción en sus significados que las unidades de la lengua general, sus significantes revelan, en un gran porcentaje, comportamientos similares a los del lenguaje natural que merecen ser tenidos en cuenta. Ejemplos como villancico, estribillo, zarzuela, ópera, tono, re, etc. demuestran que buena parte de las unidades léxicas de la música no obedecen a criterios de univocidad donde se da una perfecta analogía permanente, estable y estática entre el concepto, entre lo referido -el elemento independiente de las lenguas y supuestamente universal- y su significado. Al contrario, la música se desarrolla en un contexto y, por eso mismo, posee ampliamente conceptos complejos, poliédricos y, sobre todo, variables que convendría problematizar a la hora de abordar la narración historiográfica.

La musicología hace tiempo que sintió la necesidad de atender a su léxico e incluso de servirse de la investigación lingüística como herramienta auxiliar para proponer nuevos acercamientos a ámbitos y periodos concretos de la historia de la música. No obstante, desde aquí queremos reivindicar que la multiplicidad de dinámicas y aspectos que envuelven a las unidades léxicas de la música reclaman un espacio propio y autónomo. 